\title{
Influence of Aging in Outcomes of Patients Undergoing Percutaneous Nephrolithotomy for Staghorn Stones : A retrospective comparative study
}

\author{
Murat Sahan ${ }^{1}$, Serkan Yarımoğlu ${ }^{1}$, Metin Savun ${ }^{2}$, Onur Erdemoglu ${ }^{3}$, and Tansu \\ Degirmenci $^{4}$ \\ ${ }^{1}$ Izmir Bozyaka Training and Research Hospital \\ ${ }^{2}$ Siverek State Hospital \\ ${ }^{3}$ Affiliation not available \\ ${ }^{4}$ University of Health Sciences Izmir Bozyaka Education and Research Hospital
}

June 21, 2021

\begin{abstract}
Objective: To evaluate the effect of age on the success and complications of percutaneous nephrolithotomy (PCNL) in staghorn renal stones. Materials and Methods: The files of 182 patients who underwent single-access PCNL for staghorn renal stones between 2012 and 2017 were retrospectively analyzed. The patients were divided into two groups according to their age: those aged $<65$ years were defined as Group- 1 and those aged[?]65 years as Group-2. The demographic characteristics and perioperative and postoperative results were compared between the two groups. Results: Of the patients with staghorn renal stones,139 were in Group-1 and 43 were in Group-2. The mean age of the patients was $43.9 \pm 10.6$ years for Group-1 and $67.8 \pm 2.1$ years for Group-2( $\mathrm{p}=0.001)$. The amount of hemoglobin drop was statistically significantly higher in Group-1 ( $\mathrm{p}=0.001)$. However, blood transfusion rate was higher in Group-2 than in Group-1 (18.6\% and $7.2 \%$, respectively). The stone-free rate was $54.7 \%$ in Group- 1 and $67.4 \%$ in Group-2( $\mathrm{p}=0.139)$. According to the evaluation of the overall complication rates, $34.5 \%$ of the patients in Group-1 and $46.5 \%$ of those in Group-2 developed complications( $\mathrm{p}=0.206)$. According to the Clavien scoring system, the rate of minor complications was found to be $22.3 \%$ in Group- 1 and $41.9 \%$ in Group- 2 , and the difference was statistically significant $(\mathrm{p}=0.012)$. The major complication rates were determined as $4.7 \%$ and $12.2 \%$ for Group- 1 and Group- 2 , respectively $(\mathrm{p}=0.155)$. The number of patients with Clavien grade- 2 complications was statistically higher in the elderly patient group $(\mathrm{p}=0.019)$. Conclusions: PCNL can be used as an effective and safe treatment method in the treatment of complex stones in elderly patients.
\end{abstract}

\section{ABSTRACT}

Objective:

To evaluate the effect of age on the success and complications of percutaneous nephrolithotomy (PCNL) in staghorn renal stones.

\section{Materials and Methods:}

The files of 182 patients who underwent single-access PCNL for staghorn renal stones between 2012 and 2017 were retrospectively analyzed. The patients were divided into two groups according to their age: those aged $<65$ years were defined as Group- 1 and those aged[?]65 years as Group-2. The demographic characteristics and perioperative and postoperative results were compared between the two groups.

\section{Results:}


Of the patients with staghorn renal stones, 139 were in Group- 1 and 43 were in Group-2. The mean age of the patients was $43.9 \pm 10.6$ years for Group- 1 and $67.8 \pm 2.1$ years for Group- $2(\mathrm{p}=0.001)$.

The amount of hemoglobin drop was statistically significantly higher in Group-1 ( $p=0.001)$. However, blood transfusion rate was higher in Group-2 than in Group-1 (18.6\% and 7.2\%, respectively). The stone-free rate was $54.7 \%$ in Group- 1 and $67.4 \%$ in Group- $2(\mathrm{p}=0.139)$. According to the evaluation of the overall complication rates, $34.5 \%$ of the patients in Group- 1 and $46.5 \%$ of those in Group- 2 developed complications( $\mathrm{p}=0.206)$.

According to the Clavien scoring system, the rate of minor complications was found to be $22.3 \%$ in Group-1 and $41.9 \%$ in Group-2, and the difference was statistically significant $(\mathrm{p}=0.012)$. The major complication rates were determined as $4.7 \%$ and $12.2 \%$ for Group- 1 and Group- 2 , respectively $(\mathrm{p}=0.155)$. The number of patients with Clavien grade- 2 complications was statistically higher in the elderly patient group $(\mathrm{p}=0.019)$.

\section{Conclusions:}

PCNL can be used as an effective and safe treatment method in the treatment of complex stones in elderly patients.

\section{What's already known about this topic?}

Currently, percutaneous nephrolithotomy are the most favored treatment option for staghorn renal stones. However, there are concerns related to the safe applicability of PCNL in geriatric patients with staghorn stones, who have bleeding tendency and low cardiopulmonary performance.

\section{What does this article add?}

This study showed that PCNL could be effectively and safely applied in the elderly population for the treatment of staghorn renal stones. However, since minor complications after PCNL are seen at a higher rate in this patient group.

\section{Introduction:}

Globally, individuals aged 65 and over are defined as the 'elderly population' (1). Especially in developed and developing countries, the decrease in birth rates, as well as the prolongation of life expectancy at birth and advanced age have led to a relative increase in the elderly population and its share in the total population. As a result of this increase, more elderly patients require treatment due to urinary system stones. Staghorn stones are of particular concern in this age group because the management of such stones may require lengthy and multiple procedures and has a high complication rate.

Staghorn stones are branching and usually infected stones that cover a large part of the collecting system (2). Failure to achieve stone-free status may lead to the complete loss of function and sepsis in the kidney by destroying the renal parenchyma. Guidelines recommend percutaneous nephrolithotomy (PCNL) as the standard treatment modality for renal stones $>2 \mathrm{~cm}$ (3). Success in patients with PCNL reach 96.1\% (4). However, since multiple percutaneous accesses may be required to remove all stone branches in staghorn stones, it is very difficult to achieve success in these patients (5). Therefore, as reported in previous studies, stone-free rates in staghorn stones can decrease to $56.9 \%$ (6). In addition to these low stone-free rates after PCNL, staghorn stones also have high complication rates. In a prospective randomized study, the intraoperative complication rate of PCNL applied in the treatment of staghorn stones was found to be $16.3 \%$, and the postoperative major complication rate was determined as $18.6 \%$ (7)

There are concerns related to the safe applicability of PCNL in geriatric patients, who have bleeding tendency and low cardiopulmonary performance. Therefore, in this study, we aimed to compare the results between elderly and younger patients who underwent PCNL for staghorn stones.

\section{Materials and Methods:}


This retrospective study was conducted between April 2012 and January 2017 with patients who had undergone PCNL for staghorn stones. Patients with a skeletal deformity, congenital kidney anomalies, coagulopathy, and solitary kidneys, cases requiring multiple accesses, and patients without staghorn stones were excluded from the study. A total of 182 staghorn stones were divided into two groups according to patient age: those aged $<65$ years old were defined as Group- 1 and those aged [?]65 years as Group-2. The demographic, perioperative and postoperative data were compared between these two groups.

All the patients were evaluated preoperatively using standard non-contrast abdominal computed tomography (CT). The patients' demographic and preoperative characteristics, including operation side and history, stone burden, gender, metabolic syndrome, and stone density were recorded. In addition, intraoperative and postoperative results (operation and fluoroscopy time, nephroscopy time, calyx accessed, complications, and stone-free status) were examined. Postoperative complications were evaluated according to the Clavien scoring system (8).

After the urine culture of the patients was confirmed to be negative, they were taken to the operation room.

Stone burden was calculated in square millimeters in all patients (length $\mathrm{x}$ width $\mathrm{x} \pi \mathrm{x} 0.25$, where 3.14 was taken as the mathematical constant) (9). For staghorn stones, this calculation was performed separately for each calyceal stone and the sum of all values was accepted as the result. All PCNL operations were performed by experienced urologists. Success was considered as complete stoneless or detection of $<4 \mathrm{~mm}$ stones on control CT performed at the first postoperative month.

Operation technic

After placing 5 or $6 \mathrm{~F}$ ureter catheters under general anesthesia, subcostal or intercostal access was achieved in all patients with an 18-gauge needle with fluoroscopic guidance in the prone position depending on the location of the stone and the anatomy of the kidney. The entry site was dilated up to $30 \mathrm{Fr}$ using Amplatz dilators, and the collecting system was entered with a nephroscope. Lithotripsy was performed with a pneumatic lithotriptor (Vibrolith; Elmed, Ankara, Turkey). A 14 F nephrostomy tube was inserted postoperatively in all patients.

Statistical Analysis

Statistical Package for the Social Sciences (SPSS IBM Corp.; Armonk, NY, USA) version 22 software package was used to analyze the data. The independent-samples t-test, chi-square test, and Fisher's exact test were used to compare the two groups. Quantitative data were expressed as mean \pm standard deviation values in tables. Categorical data were presented as numbers (frequency) and percentages (\%). Data were analyzed at a $95 \%$ confidence level, and p value was considered significant if less than 0.05 .

\section{Results:}

There were 139 patients in Group-1 and 43 patients in Group-2. The mean ages of the patients were $43.9 \pm$ 10.6 and $67.8 \pm 2.1$ years in Group- 1 and Group-2, respectively $(\mathrm{p}=0.001)$. The mean stone size was 899 $\pm 292 \mathrm{~mm}^{2}$ in Group-1, it was 1,008 $\pm 208 \mathrm{~mm}^{2}$ in Group-2 $(\mathrm{p}=0.736)$. Patient and stone characteristics were similar in both group. (Table 1).

When we examined the operative data, we determined that the durations of operation, nephroscopy and fluoroscopy were similar between the groups $(\mathrm{p}=0.968, \mathrm{p}=0.149$, and $\mathrm{p}=0.342$ respectively). (Table 2).

When we evaluated the postoperative results, we observed that the amount of hemoglobin drop was statistically higher in Group-1 ( $\mathrm{p}=0.001)$. However, the need for blood transfusion was found to be higher in Group-2 than in Group-1 (18.6\% and 7.2\%, respectively). Length of hospital stay and duration of nephrostomy tube were similar between two groups $(\mathrm{p}=0.855$ and $\mathrm{p}=0.352$, respectively). The stone-free rate was calculated as $54.7 \%$ in Group-1 and $67.4 \%$ in Group-2 $(\mathrm{p}=0.139)$. Concerning the total complication rates, $34.5 \%$ of patients in Group- 1 and $46.5 \%$ of those in Group-2 were observed to develop complications $(\mathrm{p}=0.206)$. Postoperative complications and related results are shown in detail in Table 3. 
When we examined the subgroups of complications according to the Clavien scoring system, the rate of minor complications was found to be $22.3 \%$ in Group- 1 and $41.9 \%$ in Group-2 $(\mathrm{p}=0.012)$. The major complication rates were determined as $4.7 \%$ and $12.2 \%$ in Group- 1 and Group- 2 , respectively $(\mathrm{p}=0.155)$. In addition, the rate of Clavien grade- 2 complications was statistically higher in the elderly group $(p=0.019)$ ( Table 4$)$.

\section{Discussion:}

The increase in the aging population has resulted in more renal stones being detected in geriatric patients. It is important to determine the most appropriate approach when managing renal stones in geriatric patients because of age-related cardiovascular and pulmonary system deterioration and presence of multiple comorbidities. In elderly patients with multiple comorbidities, observation may be an option for asymptomatic small stones. However, in elderly patients, stone growth is observed to occur over a shorter time, and urinary tract infection causes pain that requires obstruction and analgesics (10), adversely affecting their kidney functions. Although PCNL is accepted as an effective and safe method in large kidney stones, it can result in major complications. One of the review by Skolarikos et al. stated that the rate of major complications after PCNL were septicemia (0.9-4.7\%), bleeding requiring an intervention (0.6-1.4\%), pleural injury (2.3-3.1\%), and colonic injury $(0.2-0.8 \%)(11)$. Changes in the cardiorespiratory reserve of elderly patients make them less tolerant to bleeding or septic complications (12). Therefore, a detailed evaluation and a careful approach are required in the management of renal stones in elderly patients.

Despite advances in instrumentation and technology, staghorn stones are difficult to manage. In a study retrospectively reviewing 42 PCNL procedures performed on 33 patients aged 65 years and older compared with younger patients (47\% of the stones were staghorn), $82 \%(27 / 33)$ of the patients were determined to achieve stone-free status or have fragments $<5 \mathrm{~mm}$ at three months after surgery. In this study, PCNL was shown to be a safe and effective treatment for elderly patients, even in the presence of renal stones; however, a higher rate of transfusion was required in this group (13). Şahin et al. reported the PCNL results of 27 patients aged over 60 years and compared them to 178 PCNL procedures performed in 166 younger patients at the same time interval (14). Only $25 \%$ of the patients had staghorn renal stones, and the success rate was $89 \%$ and $92 \%$ for elderly and younger patients, respectively. In contrast to previous studies reporting higher stone-free rates $(78-93 \%)$ after PCNL in staghorn renal stones $(5,15)$, the success rates obtained from the current study including only complete staghorn stones were found to be $67.4 \%$ and $54.7 \%$, for the elderly and younger groups, respectively. This lower rate of success can be explained by technical limitations, such as the exclusion of partial staghorn stones, use of only one access point for each patient, lithotripsy being performed only with a pneumatic lithotripter, and not using a flexible nephroscope. Similar to our study, Kuzgunbay et al., who performed 47 PCNL procedures in 45 patients aged 65 years with complete staghorn stones and compared their data to 37 younger patients, found the success rate after the first procedure as $53 \%$ in the elderly group and $37.8 \%$ in the control group (16).

In our study, in which only complete staghorn stones were included, the stone sizes were similar between elderly and younger patients, which shows the comparability of the two groups in terms of stone burden. Furthermore, length of hospital stay, operation and fluoroscopy durations, and success rate were found to be similar in the elderly and younger groups. Therefore, we consider that advanced age does not have a negative effect on intraoperative parameters and postoperative outcomes in complex stones. However, in our study, while the decrease in hemoglobin was significantly higher in younger people $(1.9 \pm 1.3 \mathrm{~g} / \mathrm{dl}$ versus $1.3 \pm 1.2 \mathrm{~g} / \mathrm{dl}, \mathrm{p}=0.001)$, the rate of transfusion requirement was moderately higher in the elderly $(7.2 \%$ versus $18.6 \%$ ). This suggests that the rate of transfusion was higher in the elderly relative to the decrease in hemoglobin. The higher transfusion rate in the elderly indicates that they have lower tolerance to hemoglobin drop. Stoller et al. found higher blood transfusion rates after PCNL in elderly patients with complex renal stones (13). Şahin et al. reported the transfusion rates after PCNL as $21 \%$ in elderly patients and $18 \%$ in younger patients (14). In another study, the transfusion rate after PCNL in staghorn renal stones was detected as $10.6 \%$ in the elderly and $13.5 \%$ in the younger group, while the hemoglobin change was $1.46 \pm$ $1.29 \mathrm{~g} / \mathrm{dl}$ and $1.70 \pm 1.33 \mathrm{~g} / \mathrm{dl}$, respectively (16).

Percutaneous nephrolithotomy is recognized as an effective and safe treatment modality for large kidney 
stones. Although the efficacy of the procedure has been proven, complication rates of up to $83 \%$ have been reported in the literature, including bleeding requiring transfusion ( $7 \%$ ), organ damage $(0.4 \%)$, and infectious events (up to $33 \%$ ) (17,18). Elderly patients tend to have more comorbidities, making them more vulnerable to fatal bleeding and septic complications (19). In a study by Okeke et al., the overall complication rate after PCNL was significantly higher in elderly patients (20). However, Karami et al. reported that age alone was not a predictive factor for high complication rates (21). In another study, no major complications were observed after PCNL in staghorn renal stones in the elderly and younger population, and their minor complication rates were similar (16). In contrast, in our study, there was a higher rate of minor complications, such as bleeding requiring transfusion in eight and postoperative fever requiring antibiotic change in seven of the 43 patients in the elderly group, while sepsis, pneumothorax and bowel injury were not observed in either group. This suggests that elderly patients are less tolerant of bleeding and less resistant to infectious events because they are more prone to having comorbidities. To our knowledge, this is the first study to separately evaluate post-PCNL complications in elderly patients with staghorn renal stones according to the Clavien-Dindo classification.

There are some limitations to our study. First, it had a retrospective design and a limited number of patients. Second, there was no long-term comparison of surgical complications. Finally, further prospective studies are needed with a larger series of geriatric patients with staghorn stones, focusing specifically on complications, as well as evaluating their medical complications.

\section{Conclusions:}

This study showed that PCNL could be effectively and safely applied in the elderly population for the treatment of staghorn renal stones. However, since minor complications after PCNL are seen at a higher rate in this patient group, it is necessary to be more cautious in terms of possible complication development.

Funding: None.

\section{Author Disclosure Statement:}

Conflict of interest: None

Ethical Standards: Informed consent was obtained pre-operatively from all of our patients which were included in our study.

Ethical compliance: All procedures performed in studies involving human participants were in accordance with the ethical standards of the institutional and/or national research committee and with the 1964 Helsinki declaration and its later amendments or comparable ethical standards.

\section{References}

1. World Health Organization (2011). Definition of an older or elderly person. Health statistics and health information systems: World Health Survey; http://www.who.int/healthinfo/survey/ageingdefnolder/en/index.html

2. Ganpule AP, Desai M: Management of the staghorn calculus: Multiple-tract versus single-tract percutaneous nephrolithotomy. Curr Opin Urol 2008;18:220-223.

3. Torricelli FCM, Monga M: Staghorn renal stones: what the urologist needs to know. Int Braz J Urol. 2020;46:927-933.

4. Wollin DA, Preminger GM: Percutaneous nephrolithotomy: complications and how to deal with them. Urolithiasis 2018; 46:87-97

5. Desai M, Jain P, Ganpule A, Sabnis R, Patel S, Shrivastav P: Developments in technique and technology: the effect on the results of percutaneous nephrolithotomy for staghorn calculi. BJU Int. 2009;104:542-548. 
6. Desai M, De Lisa A, Turna B, Rioja J, Walfridsson H, D'Addessi A, et al: The clinical research office of the endourological society percutaneous nephrolithotomy global study: Staghorn versus nonstaghorn stones. J Endourol 2011;25:1263-8.

7. Al-Kohlany KM, Shokeir AA, Mosbah A, Mohsen T, Shoma AM, Eraky I, et al: Treatment of complete staghorn stones: a prospective randomized comparison of open surgery versus percutaneous nephrolithotomy. J Urol 2005;173:469-473

8. Dindo D, Demartines N, Clavien PA: Classification of surgical complications: a new proposal with evaluation in a cohort of 6336 patients and results of a survey. Ann Surg. 2004;240:205-13.

9. Tiselius HG, Andersson A: Stone burden in an average Swedish population of Stone formers requiring active Stone removal: how can the stone size be estimated in the clinical routine? Eur Urol 2003;43:275-81.

10. Burgher A, Beman M, Holtzman JL, Monga M: Progression of nephrolithiasis: long-term outcomes with observation of asymptomatic calculi. J Endourol 2004;18:534-9.

11. Skolarikos A, de la Rosette J: Prevention and treatment of complications following percutaneous nephrolithotomy. Curr Opin Urol 2008;18:229-234.

12. Tonner PH, Kampen J, Scholz J: Pathophysiological changes in the elderly. Best Pract Res Clin Anaesthesiol 2003;17:163-177.

13. Stoller ML, Bolton D, St Lezin M, Lawrence M: Percutaneous nephrolithotomy in the elderly. Urology 1994;44:651-654.

14. Sahin A, Atsü N, Erdem E, Oner S, Bilen C, Bakkaloğlu M, et al: Percutaneous nephrolithotomy in patients aged 60 years or older. J Endourol. 2001;15:489-91.

15. Soucy F, Ko R, Duvdevani M, Nott L, Denstedt JD, Razvi H: Percutaneous nephrolithotomy for staghorn calculi: a single center's experience over 15 years. J Endourol. 2009;23:1669-73.

16. Kuzgunbay B, Turunc T, Yaycioglu O, Kayis AA, Gul U, Egilmez T, et al: Percutaneous nephrolithotomy for staghorn kidney stones in elderly patients. Int Urol Nephrol. 2011;43:639-43.

17. Michel MS, Trojan L, Rassweiler JJ: Complications in percutaneous nephrolithotomy. Eur Urol 2007;51:899-906.

18. Cracco CM, Scoffone CM: ECIRS (Endoscopic Combined Intrarenal Surgery) in the Galdakao-modified supine Valdivia position: a new life for percutaneous surgery? World J Urol 2011;29:821-7.

19. Akman T, Binbay M, Ugurlu M, Kaba M, Akcay M, Yazici O, et al: Outcomes of retrograde intrarenal surgery compared with percutaneous nephrolithotomy in elderly patients with moderate-size kidney stones: a matched-pair analysis. J Endourol 2012;26:625-9.

20. Okeke Z, Smith AD, Labate G, D'Addessi A, Venkatesh R, Assimos D, et al: Prospective comparison of outcomes of percutaneous nephrolithotomy in elderly patients versus younger patients. J Endourol 2012;26:996-1001.

21. Karami H, Mazloomfard MM, Golshan A, Rahjoo T, Javanmard B: Does age affect outcomes of percutaneous nephrolithotomy? Urol J 2010;7:17-21.

\section{Hosted file}

Table.docx available at https://authorea.com/users/398183/articles/527151-influence-ofaging-in-outcomes-of-patients-undergoing-percutaneous-nephrolithotomy-for-staghornstones-a-retrospective-comparative-study 